\title{
Ways and Challenges of Product Labelling for the Visually Impaired
}

\author{
Siti Nabihah Mohamad Rozy', Verly Veto Vermol1,2, Shahriman Zainal Abidin 1,2, Rusmadiah Anwar1,2 \\ ${ }^{1}$ Formgiving Design Research Group, Faculty of Art \& Design, Universiti Teknologi MARA, 40450 Shah Alam, Malaysia \\ ${ }_{2}^{2}$ National Design Centre, Universiti Teknologi MARA, 40450 Shah Alam, Selangor Darul Ehsan, Malaysia \\ nabihahrozy@gmail.com, Verly@uitm.edu.my, shahrima.z.a@uitm.edu.my, rusma935@uitm.edu.my \\ Tel of 1st Author: +6017-6644926
}

\begin{abstract}
The conceptualizing process plays an important role in assisting designers' creativity in form and styling development. It contributes to representing the cultural elements before product transformation, which has a limited investigation. This research aims to identify the metaphorical form element that conveys the brain impaired as factors of selection and defining form development of the humanoid robot embodiment. Design Protocol Analysis obtains to into design linguistic interpretations and synthesizing design based on perceptual product experience. Findings have outlined the theory of metaphorical form element selection and identification that could represent brain impaired product in assisting humanoid robotic acceptance among autism.
\end{abstract}

Keywords: braille; visually impaired; tactile; labelling tool.

eISSN: 2398-4287@ 2021. The Authors. Published for AMER ABRA cE-Bs by e-International Publishing House, Ltd., UK. This is an open access article under the CC BYNC-ND license (http://creativecommons.org/licenses/by-nc-nd/4.0/). Peer-review under responsibility of AMER (Association of Malaysian Environment-Behaviour Researchers), ABRA (Association of Behavioural Researchers on Asians/Africans/Arabians) and CE-Bs (Centre for Environment-Behaviour Studies), Faculty of Architecture, Planning \& Surveying, Universiti Teknologi MARA, Malaysia.

DOI: https://doi.org/10.21834/ebpj.v6iSI5.2933

\subsection{Introduction}

Blind people face several visual challenges every day. It begins with figuring out their spot upon reading the label on a frozen dinner. Although digital innovations in this technological era support such screen readers, GPS, computer sensors and others, their capability to carry out their day-to-day lives is still a struggle (Brady, 2014; Throughton, 1992; Vermol, 2017). The U.S. reported over $87 \%$ of participants with visual impairments to find it very hard to perform daily tasks such as reading (Goldstein, 2014). They still required assistance to act as an ordinary user. That comprises the activity of locating groceries and finding their care products. They always possess trouble in classifying the products because of the non-inclusivity of labelling for the visually impaired. According to the Department of Statistics Malaysia, the total population in 2016 is estimated at 31.7 million with $68.6 \%$ Bumiputra, Chinese (23.4\%), Indians (7\%) and others (1\%). In 2004, the government had conducted a National Eye Survey II and found out of the 31.7 million, 413,000 people in Malaysia over the age of 50 have vision problems, with 113,000 of them are reportedly blind, and the rest are affected by cataracts. While this number may seem like a minority, it is important to know that the blind also deserves the same quality of life as normally sighted people, and be worthy of an independent living experience.

eISSN: 2398-4287C 2021. The Authors. Published for AMER ABRA cE-Bs by e-International Publishing House, Ltd., UK. This is an open access article under the CC BYNC-ND license (http://creativecommons.org/licenses/by-nc-nd/4.0/). Peer-review under responsibility of AMER (Association of Malaysian Environment-Behaviour Researchers), ABRA (Association of Behavioural Researchers on Asians/Africans/Arabians) and cE-Bs (Centre for Environment-Behaviour Studies), Faculty of Architecture, Planning \& Surveying, Universiti Teknologi MARA, Malaysia.

DOI: https://doi.org/10.21834/ebpj.v6iSI5.2933 


\subsection{Literature Review}

\subsection{Braille Literacy and The Design Principle}

Braille is a tactile system in which dots emboss to represent letters, symbols, and numbers to be read by touch. It is a primary method of reading and writing for the blind (Ryles, 2000; Kalra et al., 2008; Kway et. al., 2010). According to Troughton (2014), literacy defines as the ability to read and write at a point where daily lives needs can be met. It is a continuum from basic reading and writing skills, to various technical literacies. Over the years, Braille literacy has been declining (Royal Nation Institute of Blind People; Vermol et al., 2017; Vermol et al., 2018) due to the development of world technologies that show the existence of electronic text and user assistive software. It affected Braille and was progressively neglected. Sakina Mohamed (2019) reported a shortage of experts who can convert conventional texts to Braille in Malaysia. Therefore, through collective studies by Vermol et al., (2016; 2018) explained, further research studies need to conduct before the development of touch technology within the blind user and designer mutual understanding. The activity of publishing materials in Braille is also describing to be time-consuming and labour-intensive. The traditional method of writing Braille itself creates formidable challenges to literacy. Braille literacy is closely related to the availability of Braille printing tools in the market. Ringlein (1998) mentioned several other ways to be creative with the Braille labelling system. Some of the very few tools to print Braille are as follows:

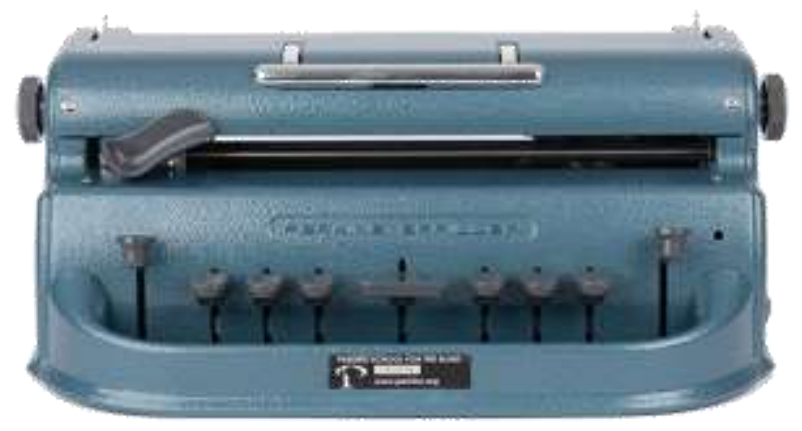

Fig. 1: Perkins Brailler (Perkins, 2006)

\subsection{Slate and Stylus}

The traditional set of slate and stylus is the most portable and dependable tool for writing in Braille. It considers like a sighted person's pen and pencil for the blind. An awl stylus is used to press the dots into thick paper and is done from right to left or backward writing skill (Hadley, 2019). Figure 2 shows a set of slate and stylus that is commonly used to write in Braille.

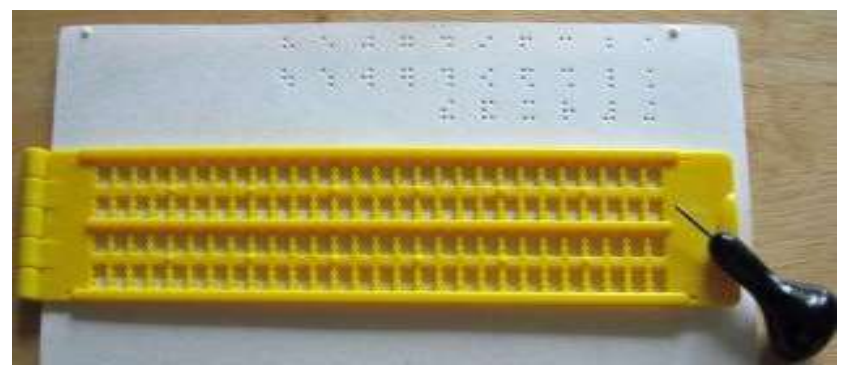

Fig. 2: Slate and Stylus (Blaevoet, 2014)

Although the tool is inexpensive, portable, and simple to use (Kway et al., 2010), the requirement to write in reverse makes the process of learning to read and write difficult especially for those with minimal training (Marwan et al. 2017; Hadley, 2019). Kway et.al. (2010) reported that the usage of slate and stylus among the blind in Malaysia is not as common as it is overseas, due to the understanding that the students and training teachers think it is a hassle to master the skills of writing backwards when using this tool. Other than that, the lack of proper technique and module to teach the use of slate and stylus at the training programs provided by both teacher training institutes and tertiary institutions also affect the minimal use of slate and stylus among the visually impaired in Malaysia (Kway et al., 2010; Anwar \& Vermol, 2020).

\subsection{Dot Label Maker}

The 6Dot Label Maker is a hi-tech Braille labelling machine with a keyboard familiar to Perkins Brailler, with minimal sound compare to the noisy Perkins typewriter. The portable label maker is ergonomically designed for easily used offer powered embossing for more accurate and durable Braille dots. The 6 Dot Label Maker also includes a built-in cutter for automatically cut and score each label neatly (Logantech, 2019). With all of these extensive features in one design (product), 6Dot Label Maker was sold at a high-end price and only available in the US. 


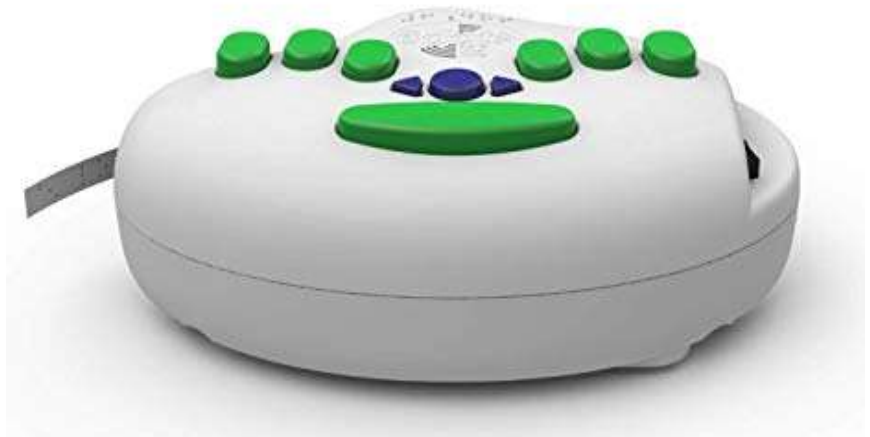

Fig. 3: 6Dots Label Maker (from Logantech, 2019)

\subsection{Vrailler}

Vrailler, as seen in Figure 4. is a result of Korean products. Designers aim to create an affordable, effective, and portable label printer that allows users to print Braille easier. It acts as an educational tool designed to raise disability awareness. It has features that allow the user to do Braille printing anywhere. These features are still continually upgraded to ensure their effectiveness to the blind community.

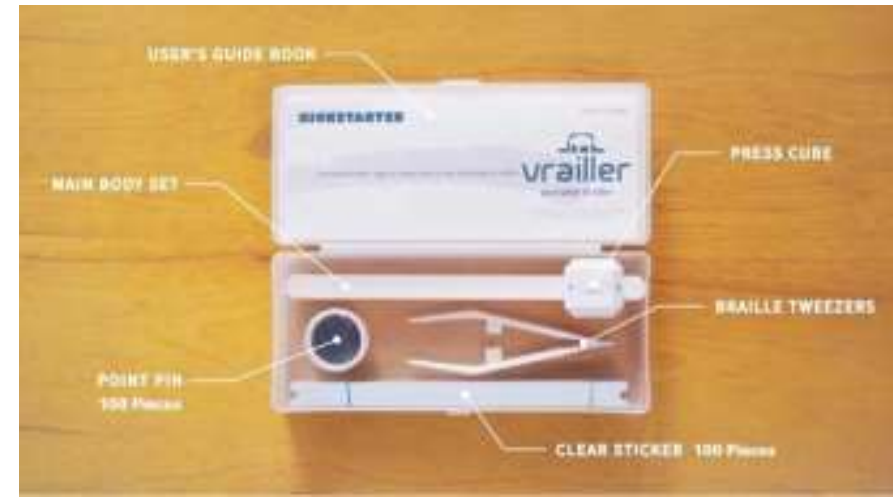

Fig. 4: A set of Vrailler (Kickstarter, 2019)

\subsection{Findings}

\subsection{The Need and Challenges for Braille Labels}

Existing products stick-on Braille labels in the market used to identify a similar product with different colours. A remarkable conventional yet creative way of distinguishing products is by using different shaped craft beads that are attached with a safety pin to the product (gulve et al., 2017). In which, the limitation faced by the user is to always keep track of which shapes represent each (Anwar, 2016). According to the Medicines and Healthcare products Regulatory Agency (2016), it is a requirement for the medicine and healthcare products to be labelled and printed in Braille. It has become a common practice for every product of pharmaceutical product to know the details of the medication's info. However, it is very challenging for the visual impairment to read the product information without unspecified Braille labels, approximately to help by other sighted people. The lack of Braille types of equipment available in the public disallows people with visual impairment to move freely without the worry of causing trouble to others. The chairman of the Society of the Blind in Malaysia (SBM) was reported that the blind face problems in places such as elevators, where there are no buttons in Braille, moreover a restaurant where the menus are not readable for the blind. In an ideal world, all directions should be designed with tactile markings with large, clear contrasting letters, including numbers, so the customers could practice them efficiently. The ability to label clothing, foods and domestic appliances around the house helps blind people to live independently. The problem usually arises with a common daily item such as the washing machine. It is almost impossible for a blind person to handle. This problem can be solved by designing tactile or Braille markings on the control panel. It can indicate different settings on each dial (Royal National Institute of Blind People). Douglas et. al. (2009) argued that a range of technology, which included braille, offered clients more flexibility: "it was important to continue to have access to Braille - having another avenue for shopping lists, labelling things etc."

Most visually impaired people still prefer to use Braille at home. Annely Rose mentioned that she still uses Braille for lots of things in the home, for reading recipes, reading books and magazines. She has been labelling everything in Braille to know what's what, whether it's a bill or a document and et cetera. (Hadley, 2019). Based on the discussion on Hadley (2019), a lot of blind people have various ways of labelling things, with each of them try to find the cheapest and most efficient way in having Braille labels on their items. Since there is no specific Braille labelling tool available in the market, blind people have been creatively labelling their items in many 
ways - one of them by putting rubber bands on things to distinguish them from another. However, it is also noted that most of them, are comfortable is using slate and stylus for everyday note-taking activities.

\subsection{Discussions}

Based on the literature, most Braille users prefer to have a simplified tool to make Braille labels. Blind people are accustomed to the use of slate and stylus in writing and taking notes. As the price of slate and stylus is considerably cheap and affordable, many of them own at least a set of slate and stylus in their household. The slate and stylus are also widely used as an early learning tools for blind education. Furthermore, slate and stylus are low-tech means, less hassle, cheap, light and portable to carry (Blaevoet, 2014). However, the design challenge (Anwar et al., 2015) of using this kind of set is because the braille dots need a high pressure to press. Begin with the top until the bottom needs to be ingested from the right side to the left side. This reverse writing technique (see Figure 5) will need a lot of practice to be commenced. The paper flipped after the writing so readers can read it from left to right.

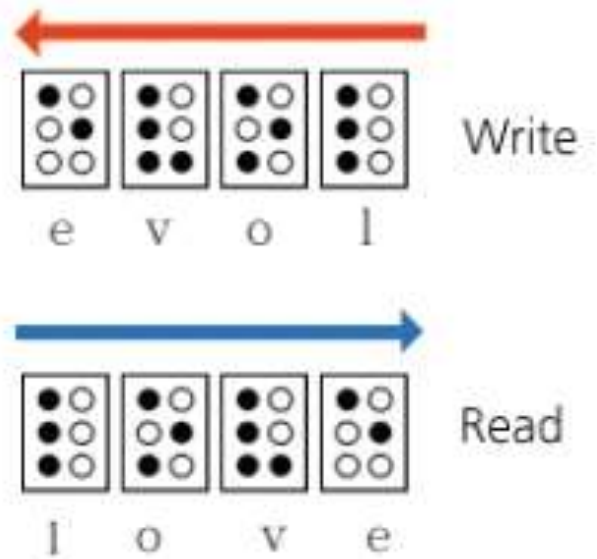

Fig. 4: Reverse writing in slate and stylus (Kickstarter, 2019)

The Vrailler, consider new in this braille industry. It is designed to minimise the difficulty of labelling activity for its consumers. The set of Vrailler come together with plastic tape, which has adhesive to stick on any surface. It eliminates the need for double tape or rubber bands, as practised by the blind to hang or stick Brailled labels on their items (Hadley, 2019). Unlike slate and stylus, the Vrailler use similar writing and reading skills in which, is from left to right and hence do not cause as many confusions as slate and stylus.

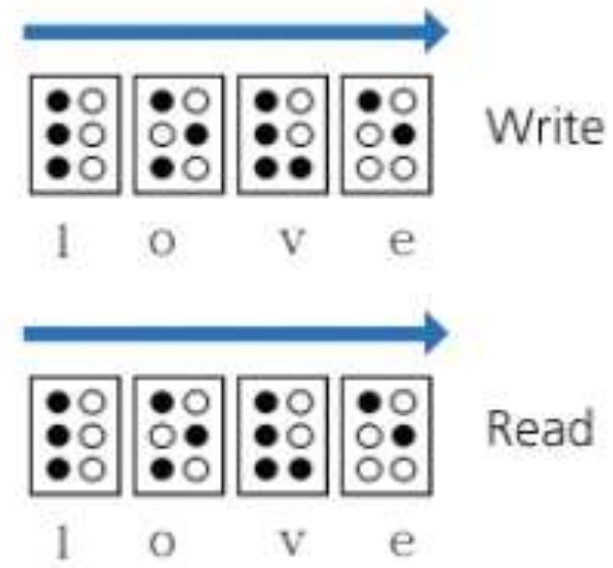

Fig. 5: One-way writing by using Vrailler

However, during testing, the manoeuvre in using Vrailler is not an as easy thought. Vrailler required its user to carefully locate small pins inside the holes to illustrate the letter. As the size of pins is small, it appears to be quite hard to handle for a sighted person. There is still an area that needs to be overcome in designing the Vrailler, to achieve its aim to provide a solution for easy labelling activity for the visually impaired. 


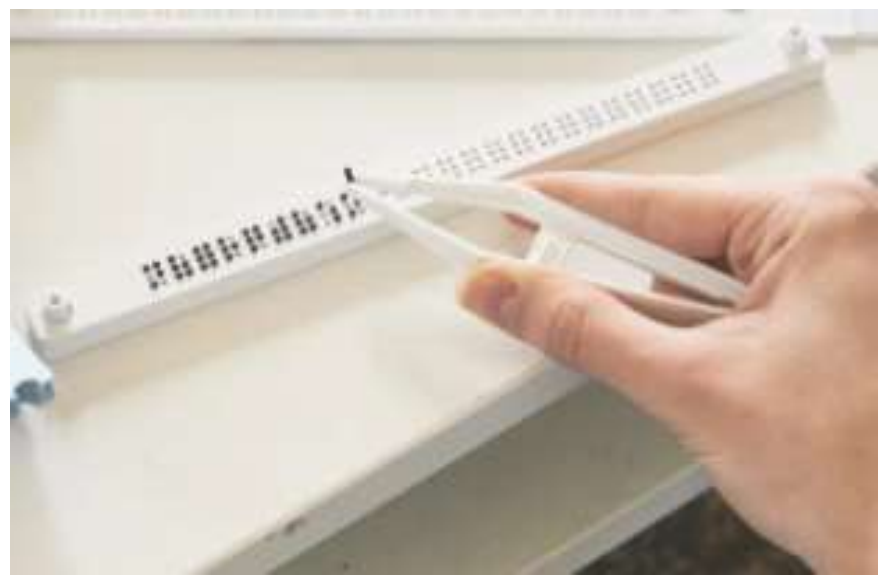

Figure 6: A user placing small pins in the holes of a Vrailler.

A brief description and features of these two labelling tools are summarized in the table below.

Table 1. Comparison between slate and stylus and Vrailler

\begin{tabular}{lll}
\hline Slate and Stylus & & Vrailler \\
\hline Portable & Portability & Portable \\
Low & Price & High \\
Right to left (Reverse writing) & Writing method & Left to right (Normal writing) \\
Left to right (Normal writing) & Reading method & Left to right (Normal writing) \\
irregular (Depending on the pressure exerted by & Braille size & Consistent \\
the user) & & (The consistency helps in a more accurate \\
& & reading) \\
\hline
\end{tabular}

\subsection{Conclusion}

In this paper, we have introduced the various ways to print Braille. It can conclude that Braille holds a very important role in the world of the blind. It acts as a way for communication that is translated through touch. To have perfect labelling to transfers information to a blind, these individuals had to face multiple challenges that include the unavailability of any tactile product labelling that is inclusive for the visually impaired. More studies are needed to complement the needs of the blind, the sustainable and impactful tool to label their personal belongings. It can be concluded that most normal sighted consumers, the blind would prefer a low-cost Braille labelling tool. To own a personal Brailler, or any other tool for labelling Braille, the blind demands for affordable brailling product that is not often available in the market. Despite the technological improvement in the nation, a low-powered tool is still preferable. It is more reliable than high-powered Braille machines for the individual blind. Last but not least, a feasible and easy to use tool for Braille labelling on the everyday product is very much desirable for the visually impaired community. All in all, this paper has managed to cover the ways and challenges faced by the visually impaired in identifying items due to the non-inclusive design in product labelling. The findings from this paper are suggested to be an assistance to analyze potential braille product labelling tools in the future development to help blind people live more independently in their everyday lives.

\section{Acknowledgements}

This research is gratefully supported by Universiti Teknologi MARA [Grant number: 600-IRMI/MYRA 5/3/REI (002/2018).

\section{References}

Anwar R. \& Vermol, V. V. (2020) Visually Impaired Learning Design Experience through In-Vitro Design Protocol. International Journal of e-Learning and Higher Education. Volume 13 (1), June 2020, Pages 17 to 29.

Anwar, R. (2016). Characterizing a syntactic pattern of formgiving in design thinking process. Shah Alam: Universiti Teknologi MARA.

Anwar, R., Hassan, O. H., \& Abidin, S. Z. (2015). A pattern in formgiving design: Giving priority to a principle solution in industrial design situation. In M. Gen, K. J. Kim, $X$. Huang, \& Y. Hiroshi (Eds.), Industrial engineering, management science and applications. Berlin: Springer.

Blaevoet, R. (2014). All Praise to the Humble Slate and Stylus! Retrieved from https://nationalbraillepress.wordpress.com/2014/06/25/all-praise-to-the-humble-slate-andstylus/

Brady, Erin \& Morris, Meredith \& Zhong, Yu \& White, Samuel \& Bigham, Jeffrey. (2013). Visual challenges in the everyday lives of blind people. 2117-2126. 10.1145/2470654.2481291. 
Douglas G. (Dr.), Franks. J. (Dr.), Weston, A. and Clements, B. 2009. Braille in the 21 st Century: opportunities, benefits, and challenges for adults with acquired sight loss. Visual Impairment Centre for Teaching and Research (VICTAR), School of Education, University of Birmingham, B15 2TT, UK.

Goldstein, J., Brown, J., Chan, T., Massof, R., \& Ramulu, P. (2014). Characterizing functional complaints in patients seeking outpatient low-vision services in the United States. Ophthalmology, 121(8). https://doi.org/10.1016/j.ophtha.2014.02.030

Gulve, K., Kathe, S., \& K., N. (2017). Braille Printer. Retrieved from https:/lijarcce.com/upload/2017/april-17/IJARCCE 9.pdf

Hadley. (2019). Embracing Braille - Using Braille at Home. Retrieved from https://hadley.edu/discussions/episode.asp?podcast=Braille\&episode=Using_Braille_at_Home

Kalra, Nidhi \& Lauwers, T. \& Dewey, D. \& Stepleton, T. \& Dias, M.. (2008). Iterative design of a Braille writing tutor to combat illiteracy. 2007 International Conference on Information and Communication Technologies and Development, ICTD 2007. 1 - 9. 10.1109/ICTD.2007.4937386. Retrieved from https://www.researchgate.net/publication/224452969_Iterative_design_of_a_Braille_writing_tutor_to_combat_illiteracy

Kway, E. H., Norani Mohd Salleh, \& Rosadah Abdul Majid (2009, 25 November 2009). Braille Writing With Slate And Stylus For Visually Impaired Students In Malaysia: A Pilot Study. Paper presented at the International Conference On Teaching And Learning In Higher Education (ICTLHE 2009), Legend Hotel, Kuala Lumpur.Mulik, O., Kway, E.H., Norani Mohd Salleh, Rosadah Abd. Majid. (2010). Slate and Stylus: An Alternative Tool for Braille Writing.

Kickstarter. (2019). Vrailler: Affordable DIY Braille Label Kit to Learn Empathy. Retrieved from ttps://www.kickstarter.com/projects/vrailler/vrailler-the-portable-and-easyto-use-braille-prin/description

Logantech. (2019). 6 Dot Braille Label Maker. Retrieved from https://logantech.com/products/6dot-braille-label-maker

Marwan, M., \& Hock, K. E. (2017). Development of Learning Aids for Visually Impaired Students using Hannafin Peck Theory. International Journal of Academic Research in Business and Social Sciences, 7(4). doi: 10.6007/ijarbss/v7-i4/2896

Medicines and Healthcare products Regulatory Agency. (2016). Retrieved 1 November 2019.

Perkins. (2016) "Perkins brailler," Catalog of Products; Howe Press of the Perkins School for the Blind.

Ringlein, A. (1998) 101 Ways to Use Braille. Retrieved from https://www.nfb.org/sites/www.nfb.org/files/images/nfb/publications/bm/bm99/bm990309.htm

Royal National Institute of Blind People. https://www.rnib.org.uk/

Ryles, R. (2000). Braille as a predictor of success. In J. M. Dixon (Ed.), Braille into the next millennium.

Sakina Mohamed (2019). Blind Students Not Getting Books They Need. Retrieved from http://www.bernama.com/en/news.php?id=179113

Troughton, M. (1992). Research and experience. In One is fun [Online]. Retrieved from http://snow.utoronto.ca/best/special/OnelsFun/ chapter_001.htm

Vermol V.V., Anwar R., Hassan O.H., Abidin S.Z. (2016) Relative Theory of Tactile Iconography Array Configuration for a Blind Group. In: Abidin S., Legino R., Noor H.

Vermol V., Anwar R., Kamaruzaman M. (eds) Proceedings of the 2nd International Colloquium of Art and Design Education Research (i-CADER 2015). Springer, Singapore.

Vermol V.V., Anwar R., Hassan O.H. \& Abidin S.Z. (2017) Designer Activity Experience: Blind UserDesigner Activity Model In Knowing Product Influence Through Blind User Perspective. Adv. Sci. Lett. 23, Pg. 10815-10821 (2017)

Vermol V.V., Anwar R., Salleh M.R., Rahim Z.A. (2018) Ceramic Craftwork Activity Observation: An Attempt to Increase Internal Identification of Blind Students Haptics Response. In: Anwar R., Mahamood M., Md. Zain D., Abd Aziz M., Hassan O., Abidin S. (eds) Proceedings of the Art and Design International Conference (AnDIC 2016). Springer, Singapore. https://doi.org/10.1007/978-981-13-0487-3_60

Vermol V.V., Abidin S.Z., Anwar R., Hassan O.H. (2018) Blind User Experience Audit: Revealing Underlying Invisible Factors in Design Experience. In: Anwar R., Mahamood M., Md. Zain D., Abd Aziz M., Hassan O., Abidin S. (eds) Proceedings of the Art and Design International Conference (AnDIC 2016). Springer, Singapore. https://doi.org/10.1007/978-981-13-0487-3_55 